\title{
¿QUIÉNES SON Y PARA QUÉ? EL PROCESO DE EXTRANJERIZACIÓN DE LA TIERRA EN ARGENTINA A PARTIR DE 2002
}

\section{Who Are They and Why? The Process of Foreign Ownership Of Land in Argentina from 2002}

\author{
Agostina Costantino ${ }^{1}$ \\ 1Sociedad de Economía Crítica de Argentina y Uruguay
}

E-mail: agoscostantino@gmail.com

\section{Resumen}

Cada vez son más los estudios en la literatura que analizan el fenómeno de la adquisición de tierras por parte de extranjeros para el caso latinoamericano, región donde parecería ser más evidente la disputa territorial entre las potencias por el control de los recursos naturales a nivel mundial. En este trabajo nos proponemos analizar quiénes son los principales actores extranjeros que comenzaron a adquirir tierras en Argentina a partir del 2002 y para qué lo están haciendo. La importancia de estas preguntas radica en reflexionar en torno al rol que un país como Argentina está jugando dentro del capitalismo mundial como proveedora de recursos naturales y como espacio geográfico de apertura de nuevas oportunidades donde valorizar el capital de los países centrales.

Palabras claves: Acaparamiento de tierras, Inversores extranjeros, Argentina, China, Recursos naturales.

\section{Abstract}

Are increasingly studies in the literature that analyze the phenomenon of land acquisition by foreigners for the case of Latin America, a region appears to be more evident territorial dispute between the powers for control of natural resources worldwide. In this paper we analyze who are the main foreign players began to acquire land in Argentina since 2002 and what they are doing. The importance of these questions lies in thinking about the role that a country like Argentina is playing within world capitalism as a supplier of natural resources and geographical space as opening new opportunities which enhance the capital of the central countries.

Keywords: Land grabbing, Foreign investors, Argentina, China, Natural resources. 


\section{INTRODUCCIÓN}

Mucho se ha estudiado ya sobre el proceso de acaparamiento de tierras por parte de extranjeros en África y Asia. Sin embargo, menos estudios que analicen este fenómeno para el caso latinoamericano, región donde parecería ser más evidente la disputa territorial entre las tradicionales potencias mundiales (como Estados Unidos y algunos países europeos) y las nuevas potencias que están peleando (económica, política y militarmente) por el control de los recursos naturales a nivel mundial (como sabemos, China, es el ejemplo más claro de esto).

En este trabajo nos proponemos analizar quiénes son los principales actores extranjeros que comenzaron a adquirir tierras en Argentina a partir del 2002 y para qué lo están haciendo. La importancia de estas preguntas radica en reflexionar en torno al rol que un país como Argentina está jugando dentro del capitalismo mundial como proveedora de recursos naturales (ahora ya no sólo a través de la exportación, sino también a través de la entrega de los propios recursos productivos) y como espacio geográfico de apertura de nuevas oportunidades donde valorizar el capital de los países centrales.

Para estudiar estas características se construyó una base de datos de tipo "catálogo de eventos" (Olzak 1989, Tilly 2002). La unidad de registro (el "evento") fue la transacción sobre la tierra, siempre que la parte adquiriente fuera extranjera y la parte cedente fuera nacional. Las fuentes de información fueron cuatro: la base de datos "Landmatrix", las memorias de los balances de las empresas (en el caso de que las mismas cotizaran en alguna bolsa de valores), los informes a la Securities and Exchange Commission -SEC- (en el caso de que cotizaran en una bolsa de Estados Unidos) e informes de prensa. ${ }^{1}$

\footnotetext{
${ }^{1}$ Se consultaron las siguientes fuentes de prensa: (i) Periódicos nacionales: Agencia de noticias RENA; Agencia Rebelión; Agencia ADN; Argenpress; Clarín, La Nación, Página 12; Infocampo; IProfesional; Tres Líneas; Mapuexpress; NextFuel; Nuevo Tiempo; El Malvinense. (ii) Periódicos provinciales: Agencia Federal de Noticias DERF (Santa Fe); Diario El Litoral (Santa Fe); Diario La Provincia (Corrientes), Diario Chaco (Chaco); Diario Río Negro (Río Negro); Informe Digital (Entre Ríos); Tribuno (Salta); Nuevo Diario (Salta), Data Chaco (Chaco); Desalambrar (Buenos Aires); Máxima Online (Entre Ríos); Uno (Entre Ríos); Los Andes (Mendoza); Valor Local (Entre Ríos); El Intransigente (Salta); OPI Santa Cruz (Santa Cruz); Campo Adentro (Entre Ríos). (iii) Periódicos extranjeros: The Times of India; The Weekend Leader; Agencia de noticias REUTERS; Levante El Mercantil Valenciano. (iv) Observatorios y blogs: Farmlandgrab, Grain, EJOLT; Greenpeace; Salvemos Juntos al Ayuní; Fundación Proteger; Infinita Renovable Prensa; Taller Ecologista; Blog del Proyecto Lemur; Asamblea en Defensa del Agua y la Tierra; Funam, Evaluación Impactos Ambientales, Beganó; Ecoportal; Redaf.
}

\section{1) El proceso de extranjerización de la tierra en el siglo XXI. Un aporte para su explicación}

En este artículo entendemos que el acaparamiento de tierras por parte de extranjeros en Argentina es resultado de su condición de país dependiente. En tanto la dependencia no es una relación de exterioridad (entre dos entidades independientes) requiere de la conjunción -contradictoriadel sistema capitalista mundial y el espacio nacional de acumulación. A efectos de exposición, llamaremos "factor externo" al primero y "factor interno" al segundo. Entonces, este fenómeno puede explicarse por la concurrencia de esos dos factores: el externo, que responde a las necesidades de expansión de los capitales de los países centrales; y el interno, relativo a la existencia de un modo de desarrollo, en los países que ceden tierras, que responda a esa necesidad de "globalización" de los capitales (Costantino 2015b). ${ }^{2}$

Un país es dependiente cuando su desarrollo está condicionado al proceso de acumulación de capitales de otros países (centrales) y, como consecuencia, presenta de manera generalizada mecanismos de transferencia de valor y excedentes hacia el exterior (Marini 1991). Estos mecanismos se presentan en varias formas, entre las cuales se encuentran:

i. $\quad$ El intercambio desigual: en la medida en que un país se especializa en la exportación de bienes cuyos precios tienden a bajar en el largo plazo respecto de los bienes que el país debe exportar, se transfieren hacia el exterior a través de la vía comercial una cantidad de divisas mayor a la que entra.

ii. El pago de servicios: en la medida en que el sistema de fletes y seguros está en manos de grandes monopolios internacionales, los países dependientes transfieren hacia el exterior una enorme cantidad de excedentes por el pago de estos servicios. Además, por esta vía también salen los pagos por la asistencia técnica (por el uso de máquinas y procesos importados) y las regalías por el derecho a usar determinadas marcas o productos.

iii. La inversión extranjera: en la medida en que aumenta en una economía la participación de empresas extranjeras en la producción, aumentan las transferencias hacia el exterior en términos de remisión de utilidades, y por la fijación de precios de transferencia entre las filiales que habilita una vía

\footnotetext{
2 Entendemos como "modo de desarrollo" a la forma en la que se acumula $\mathrm{y}$ reproduce el capital en un momento y un lugar determinados (neodesarrollismo, maquilador, agroexportador, etc.). Para un desarrollo más completo de este concepto, ver Cantamutto \& Costantino (2014).
} 
más de transferencia hacia las casas matrices y del pago de servicios (punto anterior).

iv. La fuga de capitales: en la medida en que aumentan las transferencias hacia el exterior de acuerdo a todos los mecanismos anteriores, se vulnera la función de reserva de valor de la moneda local, e incentiva a los capitalistas (de cualquier origen) a resguardar el valor apropiado en moneda de países centrales. Esta salida constituye una exacción de valor que no responde al origen de propiedad del capital ni a la búsqueda de rendimientos, sino exclusivamente al resguardo.

v. El endeudamiento externo: en la medida en que las transferencias mencionadas en los puntos anteriores generan desequilibrios en la balanza de pagos, entonces resulta cada vez más necesario el endeudamiento externo, con la consiguiente transferencia de recursos hacia el exterior en términos de pago de intereses.

En este sentido, puede entenderse al acaparamiento de tierras por parte de extranjeros como una forma particular de transferencia de valor de los países periféricos hacia el exterior, no sólo por la vía de la inversión extranjera (mecanismo iii) sino también por la vía comercial (mecanismo i) toda vez que, como veremos en el apartado 4 de este artículo, el principal destino que los inversores le dan a esta tierra es la producción de materias primas y alimentos para la exportación. ${ }^{3}$ Esta transferencia de valor hacia el exterior no supone un stock de valor ya disponible para ser exportado, sino que resulta de un proceso social de transformación de recursos comunitarios o públicos en capital (valor) a través de la desposesión violenta. El acaparamiento de tierras no es, entonces, un fenómeno exclusivamente económico, sino que requiere cambios en las dimensiones social y política del modo de desarrollo (Harvey 2004b).

De manera operacional, definiremos aquí al acaparamiento de tierras por parte extranjeros a toda adquisición (venta o arrendamiento) de más de 1000 hectáreas siempre que la parte adquiriente sea extranjera y la parte cedente sea nacional. ${ }^{4}$

\footnotetext{
3 En este artículo no mediremos cuantitativamente el monto de la transferencia de valor producido por el acaparamiento de tierras, sino que simplemente lo presentamos a modo de hipótesis.

${ }^{4}$ En base a esta definición operativa queda afuera de la base de datos el caso de Benetton. A pesar de la relevancia de este inversor en tierras patagónicas (posee más de 900,000 hectáreas), las mismas se encuentran bajo titularidad extranjera desde fines del siglo XIX, por lo que no cumple con la definición aquí utilizada (la adquisición de Benetton no implica más
}

\section{2) ¿Cuál es la situación en América Latina?}

El acaparamiento de tierras por parte de extranjeros en América Latina toma fuerzas a partir del 2008, cuando muchos de los capitales de los países desarrollados diversifican geográficamente sus inversiones. Los tres países que reciben más inversiones en adquisición de tierras por parte de extranjeros son Argentina, Brasil y Colombia, países en donde la concentración de la tierra ya era una característica importante mucho tiempo antes de que este fenómeno comenzara (Murmis \& Murmis 2010, Sauer \& Pereira-Leite 2011). ${ }^{6}$

De la mano del aumento internacional en el precio de muchos alimentos y materias primas agrícolas, los gobiernos de América Latina comienzan a incentivar la inversión extranjera en toda la cadena agroindustrial, como parte de planes de desarrollo focalizados en el aumento de la producción y exportación de estos cultivos. Por ejemplo, el "Plan Nacional de Desarrollo 2010-2014" de Colombia define a la agricultura de exportación como "una de las locomotoras del desarrollo" (Departamento Nacional de Planeación 2010), que requiere para su puesta en marcha del fomento a la inversión de proyectos agroindustriales, la ocupación de tierras baldías, concesiones sobre tierras del Estado, la utilización de tierras dentro de reservas forestales, la recuperación de tierras "inexplotadas" o "explotadas inadecuadamente". Otro ejemplo es el caso del "Plan Estratégico Agroalimentario Participativo y Federal 20102020", puesto en marcha durante el gobierno de Cristina Fernández en Argentina, donde se plantea entre los objetivos principales aumentar la producción de soja un 35\% y la producción de maíz (genéticamente modificado) un $103 \%$ para el año 2020, y al mismo tiempo aumentar las exportaciones del sector agroalimentario un $80 \%$ (con porcentajes de aumento que van desde un $49 \%$ para las

extranjerización, sino cambio de manos, la tierra ya estaba extranjerizada). Sintéticamente, en 1896 el presidente Uriburu dona las 900,000 hectáreas a diez ciudadanos ingleses (se sospecha que la razón fue la compensación por financiamiento a la "Campaña al Desierto"). Posteriormente, estos ciudadanos transfieren las tierras a la "Argentinian Southern Land Company Ltd", con sede en Londres. En 1975 "Great Western" (asentada en Luxemburgo) compra el paquete accionario de la compañía inglesa. $\mathrm{Y}$ en 1991, este paquete pasa a manos de "Edizione Holding International N.V.", holding controlado 100\% por Benetton Group (Asociación Mapu 2014).

${ }^{5}$ Un análisis más detallado del proceso de extranjerización de la tierra en América Latina puede encontrarse en Costantino (2014). Esta sección se basa en aquel artículo escrito por la autora.

${ }^{6}$ En Brasil, por ejemplo, en el año 2006 el 50\% de los establecimientos agropecuarios más pequeños ocupaba el $2.3 \%$ de la superficie (Costantino \& Cantamutto 2010); en Argentina, para el año 2002, el $77.7 \%$ de las explotaciones (de menos de 500 hectáreas) ocupaba el $22.5 \%$ de la superficie, mientras que el $11.2 \%$ de las explotaciones más grandes (de más de 1000 hectáreas) ocupaba el 62\% de la tierra (Costantino 2012). 
exportaciones hortícolas hasta un $312 \%$ para las exportaciones de girasol).

En el caso del gobierno brasilero, el incentivo a la adquisición de tierras por parte de extranjeros es aún más explícito, a través de los proyectos de colonización dirigida por el Estado y expansión agroindustrial en colaboración con gobiernos extranjeros que se implementan en el país. Un ejemplo de estos proyectos es el "Programa de Cooperación Brasilero Japonesa de Desarrollo Agrícola en el Cerrado Brasilero" para la producción de soja con financiamiento de aquel país asiático (Clements \& Fernandes 2013).

Ahora bien, a diferencia de lo que se observa en otras regiones, en América Latina la inversión extranjera tiene el mismo tratamiento que la inversión nacional, es decir no se hace ninguna discriminación, en términos de derechos y obligaciones, respecto del origen de los capitales. Por ejemplo, en Brasil se derogó en 1995 el artículo constitucional que distinguía entre compañías nacionales y extranjeras y de esta forma eliminó, las barreras a la cantidad de tierra que los inversores extranjeros pueden adquirir (Clements \& Fernandes 2013). En Colombia los extranjeros pueden invertir casi en cualquier sector sin autorización previa, ingresar capitales, maquinaria $\mathrm{y}$ tecnologías, y acceder a beneficios de la misma forma que los nacionales (Salinas-Abdala 2012). Del mismo modo, en Argentina la ley de inversión extranjera establece que estos capitales tienen igual tratamiento que un inversor local. En este sentido, no hay áreas en las cuales no puedan invertir, pueden ocupar las ganancias del modo que mejor les convenga y no tienen que requerir autorizaciones burocráticas previas (Azpiazu et al. 2012). Es cierto que en muchos de estos países (como Argentina, Bolivia o Brasil), en los últimos años se han sancionado o se están discutiendo leyes que han sido presentadas por los gobiernos como límites a la propiedad extranjera sobre la tierra. Sin embargo, en la mayoría de los casos, el alcance de estas leyes ha sido bastante limitado debido a que sólo restringen la propiedad y no otro tipo de tenencia sobre la tierra (como el arrendamiento, la aparcería, etc.); los límites a la adquisición siguen siendo considerablemente altos; no afectan derechos adquiridos; etc. (Wilkinson et al. 2012, Barberi et al. 2013).

El proceso de acaparamiento de tierras observado en otras regiones se está dando, principalmente, a través de la transferencia a inversores extranjeros de predios estatales $o$ bajo formas de tenencia comunitarias, transferencia que en muchos casos está signada de graves hechos de violencia y corrupción. ${ }^{7}$ De manera similar en América Latina muchas

${ }^{7}$ Para ver las características del proceso de extranjerización de la tierra en el resto de las regiones periféricas ver Costantino (2015a). de las inversiones en tierra se realizan en tierras estatales arrendadas por los gobiernos provinciales (como el caso de Argentina), así como en zonas de frontera desplazando a los pueblos indígenas (como el caso de los territorios afrocolombianos) o tomando pastizales (como el caso del Cerrado, en Brasil) (Borras et al. 2012). De la misma forma, el caso de Colombia resulta interesante pues aquí se han observado numerosos casos en donde el uso de violencia explícita ha resultado fundamental para desplazar campesinos y comunidades locales de tierras atractivas para el cultivo de palma aceitera (Grajales 2011).

Sin embargo, el caso latinoamericano presenta una característica que lo distingue del resto de las regiones respecto al punto señalado en el párrafo anterior: además de la adquisición de tierras estatales y comunales, los inversores extranjeros en América Latina también adquieren tierras de propietarios privados, individuos quienes venden o arriendan a empresas extranjeras. En esta región, entonces, el acaparamiento de tierras no se da sólo a través de la "acumulación por desposesión" (Harvey 2004a), es decir a través de la transformación en capital de un recurso que antes no lo era (como los recursos públicos o comunales) como en otras regiones del mundo (Asia, África o Europa del Este), sino que aquí este proceso suma un mecanismo más para la adquisición de tierras por parte de extranjeros: la venta o arrendamiento por parte de particulares.

Estos inversores son, principalmente, estadounidenses y chinos. Entre estos dos explican el $49 \%$ del total del acaparamiento de tierras por parte de extranjeros en la región (ILC 2013). A diferencia de lo observado en otras regiones donde uno $\mathrm{u}$ otro de estos dos países tiene presencia preponderante (por ejemplo, Estados Unidos en África u Oceanía; y China en Asia o Europa del este), la similar e importante presencia de ambos países, China y Estados Unidos, en Latinoamérica, entonces, parecería indicar que ésta es una región en donde actualmente ambas potencias se estarían disputando el poderío y la influencia.

\section{3) "Aquí están, éstos son"... los inversores extranjeros en tierras en Argentina}

Una característica particular de la oleada de inversiones en tierra de la década del 2000, que la diferencian de las inversiones anteriores, es la naturaleza de los inversores (tanto el país de origen como el tipo de empresa). La Tabla 1 muestra el país de origen (de acuerdo al país de asiento de las empresas) de los capitales invertidos en tierras en Argentina. El proceso de transnacionalización de las empresas y la creciente complejidad de los mecanismos e instrumentos de financiamiento de las mismas dificulta, en principio, estudiar el "origen" de los capitales: una empresa 
Ambiente y Sostenibilidad 2015 (5): 43-56

Revista del Doctorado Interinstitucional en Ciencias Ambientales

ISSN:2339-3122

Digital

puede tener asiento en las Islas Caimán para fines tributarios, cotizar en la bolsa de Wall Street y tener accionistas de cualquier parte del mundo. En este sentido, habrá que ser cuidadosos con el análisis de este apartado, excepto en aquellos casos donde fehacientemente se pueda afirmar que el origen del capital es el mismo que el lugar donde la empresa está registrada (por ejemplo, en el caso de las empresas públicas). Para construir nuestra base de datos, tuvimos en cuenta como origen de los capitales el país donde la empresa está asentada. En aquellos casos con fuertes indicios de que dicho país no coincidiera con el "origen real" (por ejemplo, en los casos de los paraísos fiscales o en el caso de las empresas que cotizan en las bolsas de valores de otro país) se realizó una investigación más profunda, empresa por empresa. Se harán los comentarios correspondientes en estos casos particulares.

Tabla 1. País de origen (6 principales) de los capitales que invierten en tierras en Argentina, 1992-2001 y 2002-2013.

\section{2-2001}

\begin{tabular}{lcccc} 
País & Hectáreas & $\begin{array}{l}\mathbf{N}^{\circ} \text { de } \\
\text { Tran }^{*}\end{array}$ & \% \\
\hline Estados Unidos & 388017 & 30.1 & 8 & 25.8 \\
$\begin{array}{l}\text { Argentina (cotiza } \\
\text { EUA) en }\end{array}$ & 314653 & 24.4 & 7 & 22.6 \\
Total Estados Unidos & 702670 & 54.5 & 15 & 48.4 \\
Italia & 340000 & 26.4 & 1 & 3.2 \\
Alemania & 126556 & 9.8 & 5 & 16.1 \\
Australia & 40000 & 3.1 & 1 & 3.2 \\
Chile & 31000 & 2.4 & 5 & 16.1 \\
\hline
\end{tabular}

2002-2013

\begin{tabular}{lcccc} 
País & Hectáreas & \% & $\begin{array}{l}\mathbf{N}^{\circ} \text { de } \\
\text { Tran }^{*}\end{array}$ & $\%$ \\
\hline Luxemburgo & 278785 & 10.6 & 21 & 24.1 \\
$\begin{array}{l}\text { Argentina (cotiza } \\
\text { EUA) }\end{array}$ & 252221 & 9.6 & 8 & 9.2 \\
Estados Unidos & 261649 & 10.0 & 9 & 10.3 \\
Total Estados Unidos & 792655 & 30.2 & 38 & 43.7 \\
China & 386000 & 14.7 & 2 & 2.3 \\
Canadá & 367469 & 14.0 & 8 & 9.2 \\
India & 273700 & 10.4 & 4 & 5.7 \\
\hline
\end{tabular}

${ }^{*}$ Número de Transacciones. Fuente: Elaboración a partir de la base de datos construida.

Durante la década del noventa, el proceso de acaparamiento estaba mucho más concentrado en inversores de Estados
Unidos y de Europa. En el caso de Estados Unidos (tanto las empresas con asiento en dicho país, como las empresas con asiento en Argentina pero que cotizan en Wall Street), se trataba en mayor medida de tres inversores: CRESUD, Tomkins Conservation y el magnate de los medios de comunicación Ted Turner. A pesar de ser presentada como "argentina" (por tener asiento allí), CRESUD es una empresa agropecuaria (producción y comercialización de granos y compra-venta de tierras) que en la primera mitad de los noventa fue adquirida por George Soros y a partir de 1998 comenzó a cotizar acciones en la Bolsa de Wall Street. La empresa, durante esta década, adquirió tierras principalmente en el norte del país para la producción soja. Tanto Tomkins Conservation como Ted Turner adquirieron en esta etapa tierras en la región del noreste y en la Patagonia con un objetivo conservacionista e inmobiliario, que generaron a partir de sus inversiones grandes conflictos por cercamientos de accesos públicos y desalojos de comunidades ocupantes de las tierras. En el caso de las empresas europeas (Thyssen de Alemania y Nettis Impianti de Italia), adquirieron tierras entre 1997 y 1999 principalmente en la región pampeana con el objetivo de producir bienes agropecuarios, estimulados por la desvalorización que tenía la tierra en dicha región y por la crisis que afectaba a los productores familiares (condiciones que facilitaban la venta y el proceso de negociación a favor del comprador).

Por otra parte, a partir de la devaluación cambia el país de origen así como el tipo de inversor que adquiere las tierras. La aparición de países como China, India o Arabia Saudita (Tabla 1) significó la incorporación de un nuevo actor en el escenario del acaparamiento de tierras en Argentina en la década del 2000: las empresas estatales extranjeras. ${ }^{8}$ Se trata de empresas estatales (Heilongjiang State Farms Beidahuang Group, Metallurgical Construction Corporation) o paraestatales (Alkhorayef Group, Walbrook Group) que han adquirido tierras en Argentina con el objetivo principal de garantizar el abastecimiento de materias primas para sus países de origen.

Por su parte, si sumamos: (i) las tierras en manos de empresas con asientos en paraísos fiscales, pero cuyos accionistas son mayoritariamente de Estados Unidos (el $10.6 \%$ del total de tierras acaparadas); (ii) las tierras en manos de empresas con asiento en Argentina, pero cuyos tenedores de acciones son principalmente estadounidenses (el 9.6\% de tierras); y (iii) las empresas con asiento en Estados Unidos (el 10\% de las tierras), podríamos afirmar sin riesgo a equivocarnos que los capitales estadounidenses

8 Arabia Saudita se encuentra en el octavo lugar en esta lista de la Tabla 1, con el $8.1 \%$ de la tierra adquirida por extranjeros entre 2002 y 2013. 
siguen liderando el proceso de acaparamiento de tierras, aunque con una participación menor que en la década anterior (30.2\% en $2002-2013$ versus $54.5 \%$ en $1992-2001)$. Se trata de empresas trasnacionales dedicadas a la producción agropecuaria y a la compra-venta de tierras. Aparece aquí, como mencionamos antes, la empresa Adecoagro creada por George Soros a partir de la adquisición de la argentina Pecom Agropecuaria (del empresario Gregorio Pérez
Companc) en el año 2002 (Adecoagro SA 2010). Esta empresa, junto con Cresud (que hasta el año 2000 también había sido propiedad de Soros), posee más del $65 \%$ de las tierras adquiridas por capitales estadounidenses en esta etapa (datos de la base construida para la investigación).

Tabla 2. Objetivos de las inversiones extranjeras en tierras en Argentina, 1992-2001 y 2002-2013.

\begin{tabular}{|c|c|c|c|c|c|c|}
\hline \multicolumn{3}{|l|}{ Objetivos } & \multicolumn{2}{|l|}{ 1992-2001 } & \multicolumn{2}{|l|}{$2002-2013$} \\
\hline Demanda & $\begin{array}{l}\text { Objetivo } \\
\text { específico }\end{array}$ & Sector & Hectáreas & $\%$ & Hectáreas & $\%$ \\
\hline \multirow{6}{*}{ Para el mercado } & \multirow{4}{*}{$\begin{array}{l}\text { Producción } \\
\text { primaria }\end{array}$} & $\begin{array}{ll}\text { Total producción } \\
\text { p/mercado }\end{array}$ & 624736 & 48.4 & 1469608 & 56.1 \\
\hline & & Sector agropecuario & 48209 & {$[77.0]$} & 846079 & [57.6] \\
\hline & & Sector minero & 2000 & {$[4.3]$} & 433469 & [29.5] \\
\hline & & Sector forestal & 116527 & [18.7] & 190060 & [12.9] \\
\hline & \multicolumn{2}{|l|}{ Turismo } & 354000 & 27.4 & 264567 & 10.1 \\
\hline & \multicolumn{2}{|c|}{ Conservación } & 311017 & 24.1 & 50649 & 1.9 \\
\hline $\begin{array}{l}\text { Demanda } \\
\text { asegurada }\end{array}$ & \multicolumn{2}{|c|}{ Garantizar abastecimiento } & - & 0 & 837006 & 31.9 \\
\hline Total & & & 1289753 & 100 & 2621830 & 100 \\
\hline
\end{tabular}

Fuente: Elaboración a partir de la base de datos construida.

El caso de Adecoagro y Pecom Agropecuaria retrata, y ha sido estudiado en otras ocasiones (Burachik 2009, Burachik et al. 2010), como ejemplo de la dificultad de las empresas argentinas para competir con las empresas extranjeras, razón por la que terminan absorbidas. La empresa Pecom Agropecuaria es vendida en 2002 por falta de acceso a financiamiento a Adecoagro. El ejemplo muestra que, incluso para el caso en que los vendedores de tierras no son productores familiares sino grandes empresarios nacionales, muchas de las ventas de tierras en la etapa de la postconvertibilidad respondieron a una retracción del capital argentino frente a la imposibilidad de competir (en este caso, por falta de financiamiento) con el capital extranjero en expansión, una muestra de la característica dependiente del proceso de acaparamiento de tierras en Argentina.

\section{4) “Qué necesidad?": los objetivos de las inversiones}

Una de las dimensiones más importantes que caracteriza al proceso de adquisición de tierras por parte de extranjeros en la década del 2000 en Argentina se refiere a los objetivos de los inversionistas. Esto es así porque esta dimensión permite visualizar al proceso de acaparamiento de tierras en
Argentina en esta etapa como una forma particular de transferencia de valor hacia los países centrales que depende, en mayor medida, de decisiones tomadas en base a cuestiones geopolíticas o de los propios procesos de acumulación de los países inversores.

Debe resaltarse que todas las operaciones de acaparamiento de tierras registradas tienen un objetivo general que consiste en valorizar el capital. Esto significa aplicar el capital de distintas formas $\mathrm{y}$ en distintos circuitos, pero siempre buscando incrementar su valor mediante la obtención de ganancias. Sin embargo, justamente, el modo en que se lleva a cabo este objetivo general introduce diferencias que podemos analizar en este apartado. La primera distinción relevante es que, de acuerdo al tipo de demanda que tengan los bienes y servicios producidos, las inversiones en tierras se diferenciarán en dos grandes grupos (Tabla 2): aquellas cuya producción se destinará al mercado (compitiendo por los compradores), y aquellas que tendrán la demanda asegurada. Estas últimas están guiadas por las necesidades específicas de un proceso de valorización en otra economía que requiere, por ello, garantizarse el abastecimiento de ciertos bienes (apartado 4.1). Por su parte, las inversiones cuya producción se destina al mercado pueden distinguirse, a su vez, en objetivos más específicos: producción primaria, 
Ambiente y Sostenibilidad 2015 (5): 43-56

Revista del Doctorado Interinstitucional en Ciencias Ambientales

ISSN:2339-3122

Digital

turismo y conservación (apartados 4.1 y 4.2). La tabla 2 muestra las hectáreas adquiridas por extranjeros según estos distintos objetivos en la etapa 1992-2001 y en la etapa 20022013.

Durante la década de los noventa, las adquisiciones de tierras se hacían para un fin productivo (y dentro de este objetivo, para la producción agropecuaria en mayor medida), y también con objetivos de conservación y turismo (sobre todo, en la etapa de precios de la tierra más bajos durante la crisis de la Convertibilidad) ver Tabla 2. Luego de la devaluación del 2002 en el país y a partir del ascenso que comienzan a tener desde los noventas algunos países en el escenario del capitalismo mundial (como China o India), el panorama de la adquisición de tierras cambia en términos de los objetivos: se duplican las tierras para producción agropecuaria, ganan importancia las adquisiciones para explotaciones mineras y surge un nuevo objetivo antes inexistente: el control de tierras para garantizar el abastecimiento de materias primas y alimentos de los países inversores. A continuación, explicaremos el devenir y las características principales de cada uno de estos objetivos.

\section{1) Producción primaria para el mercado}

Este objetivo se refiere a las adquisiciones de tierras cuyo fin explícito es la obtención de ganancias, no sólo a través de la producción primaria sino también a través de la valorización de las tierras adquiridas para lograr ganancias de capital. Las principales inversiones con este objetivo, tanto durante los noventa como en la década del 2000, son estadounidenses (a través de empresas con asiento en Argentina, en Luxemburgo y en Estados Unidos), mineras canadienses y agroalimentarias alemanas (Tabla 3 ).

Tabla 3. Países que adquieren tierras en Argentina (principales 5) para obtener ganancias de la producción agropecuaria y la comercialización de tierras, hectáreas y \% sobre el total.

\begin{tabular}{|c|c|c|c|c|c|c|c|}
\hline \multirow{3}{*}{ 1992-2001 } & País & $\begin{array}{c}\text { Argentina (cotiza en } \\
\text { EUA) }\end{array}$ & Alemania & Australia & Chile & Canadá & Total \\
\hline & Hectáreas & 314653 & 126556 & 40000 & 31000 & 22000 & 547736 \\
\hline & $\%$ & 57.4 & 23.1 & 7.3 & 5.7 & 4.0 & 100 \\
\hline \multirow{3}{*}{ 2002-2013 } & País & Canadá & Luxemburgo & $\begin{array}{c}\text { Argentina (cotiza } \\
\text { en EUA) }\end{array}$ & $\begin{array}{l}\text { Estados } \\
\text { Unidos }\end{array}$ & Chile & Total \\
\hline & Hectáreas & 367469 & 278785 & 252221 & 211000 & 99383 & 1436908 \\
\hline & $\%$ & 25.4 & 19.3 & 17.4 & 14.6 & 6.9 & 100 \\
\hline
\end{tabular}

Fuente: Elaboración a partir de la base de datos construida.

Dentro de las inversiones con este objetivo pueden encontrarse dos tipos diferenciados: por un lado, las adquisiciones de tierras por parte de empresas agroalimentarias que incluyen explícitamente el objetivo de la valorización de la tierra y, por otro lado, las adquisiciones por parte de grandes mineras trasnacionales. En el primer caso, ocupando un lugar preponderante están las inversiones de Adecoagro y Cresud que, como ya explicamos, pueden considerarse como inversiones de capitales de Estados Unidos. En los informes a la SEC de ambas empresas aparecen como los principales negocios la producción agropecuaria y la "transformación de la tierra". Respecto a la producción agropecuaria, producen granos, oleaginosas y ganado que luego venden a los grandes comercializadores y compañías industriales que la terminan exportando.
Ahora bien, además de esto, resulta importante lo que estas empresas denominan el objetivo de "transformación de la tierra". Con esto se refieren a la adquisición de tierras que las empresas definen como "sub-desarrolladas" (sabanas y pastizales naturales) y "sub-administradas" o "subutilizadas" (tierras de pasturas o de agricultura mal administrada o manejada) y, mediante la implementación de tecnología de producción de vanguardia y las mejores prácticas agrícolas, las transforman para hacerlas adecuadas para usos productivos más rentables, mejorar los rendimientos y aumentar su valor:

La compañía está buscando continuamente reciclar el capital deshaciéndose de una parte de las fincas maduras completamente desarrolladas y adquiriendo campos con 
mayor potencial de transformación. Esto permite a la empresa monetizar las ganancias de capital generadas por sus fincas totalmente transformadas y asignar su capital para adquirir tierras con mayor potencial de transformación, mejorando así el rendimiento del capital invertido (Adecoagro SA 2010).

Es decir, los objetivos de estas empresas no son sólo productivos sino también inmobiliarios y especulativos a través de la adquisición de tierra a bajo precio y su posterior venta a un precio mayor (ya sea porque el precio de la tierra aumentó como consecuencia del aumento en el precio de las materias primas o bien porque aumentó como consecuencia de las inversiones realizadas sobre la misma) (Cresud S. A. 2010, Adecoagro SA 2011). ${ }^{9}$ Entre 2006 y 2013, la empresa Adecoagro vendió más de 53000 hectáreas de tierras generando ganancias de capital por, aproximadamente, 160 millones de dólares. Según la propia empresa, estas ganancias de capital se realizaron gracias a: (i) la adquisición de tierra a precios por debajo de su valor de mercado; (ii) el proceso de transformación de la tierra aplicado por la empresa; y (iii) la apreciación que tuvo la tierra por el aumento en el precios de las materias primas (Adecoagro SA 2013).

Por otro lado, están las grandes adquisiciones de tierras por parte de las mineras que parecerían tener sólo un fin productivo (y no inmobiliario como las agroalimentarias anteriores). En este caso se destaca la canadiense Pan American Silver con más de 235000 hectáreas distribuidas en la Patagonia para la exploración y extracción a cielo abierto de oro, plata y plomo. El caso de las mineras trasnacionales resulta de suma importancia para nuestra hipótesis ya que, al ser todas extranjeras, los litigios entre ellas se resuelven en el exterior, es decir terceros países toman decisiones sobre los recursos del país donde se compra la tierra. Por ejemplo, en el año 2005 la empresa Aquiline Resourses (propiedad de Pan American Silver) demandó en Canadá a Ima Canada Corporation por uso ilegal de datos del proyecto que Pan American tenía en la provincia de Río Negro en Argentina, que culminó con el descubrimiento de Yacimiento Navidad (en la provincia de Chubut, Argentina). La justicia canadiense falló a favor de Pan American e Ima tuvo que entregarle el yacimiento descubierto (EJOLT Project 2014). En definitiva, la justicia canadiense decidió sobre la distribución y apropiación de la tierra en Argentina.

\footnotetext{
${ }^{9}$ Para una explicación detallada de cómo el objetivo inmobiliaro es también
} es una forma de apropiación de renta de la tierra ver Iñigo Carrera (2008).

\section{2) Conservación y turismo}

Presentamos en este apartado los objetivos relativos al turismo y la conservación juntos porque están muy relacionados $\mathrm{y}$, en muchos casos, hasta se trata de los mismos inversores. La literatura ha caracterizado a este tipo de adquisiciones como "acaparamiento verde", es decir la apropiación de tierra y recursos para fines ambientales, como un caso particular del acaparamiento de tierras (Fairhead et al. 2012). En general, se presenta a este fenómeno como consecuencia del proceso de mercantilización de la naturaleza, es decir como una forma de creación de nuevas oportunidades de inversión, sobre todo en la etapa neoliberal. La "naturaleza" se ha vuelto un activo de negocios que genera ingresos a partir de los "servicios ambientales" que provee (emisión de oxígeno, agua limpia, bellos paisajes, control de plagas, etc.). Como contraprestación, entonces, los propietarios de los recursos que brindan esos servicios captan fondos (públicos o de organismos internacionales) para la conservación, obtienen ingresos por el eco-turismo, la venta de bienes orgánicos y sustentables, etc. Para lograr esto se han difundido (desde la academia, la prensa, las organizaciones de la sociedad civil, etc.) determinados "lenguajes de valoración" (MartínezAlier 2009) como el de la biodiversidad en peligro, la necesidad de biocombustibles, entre otros, que, más allá de su veracidad o falsedad (aquí no se está emitiendo opinión al respecto), justifican los cercamientos de las áreas naturales para evitar la extinción de especies o compensar la emisión de gases contaminantes en otras regiones $\mathrm{y}$, además, permiten el surgimiento de mercados para comerciar los "bienes ambientales" (ahora convertidos en mercancía) (Kelly 2011). La Patagonia argentina y chilena, de hecho, es un caso paradigmático a nivel mundial en términos del acaparamiento de tierras en nombre de la protección del medio ambiente y la naturaleza, sobre todo durante la década de los noventa (Zoomers 2010).

Tanto durante la década de los noventa como en los 2000 la mayor parte de estas adquisiciones se realizó aprovechando coyunturas de precios de la tierra excepcionalmente bajos: en la primera etapa, el $97.9 \%$ de la tierra para turismo y conservación se adquirió entre 1997 y 2001, es decir durante toda la etapa recesiva del ciclo de la Convertibilidad en que los precios de la tierras estuvieron constantemente a la baja; mientras que en la segunda etapa, el $87 \%$ de la tierra para este objetivo fue comprada entre 2002 y 2003, es decir mientras la economía aún estaba en recesión luego de la crisis de la década anterior y los precios de la tierra recién estaban empezando a recuperarse (aunque aún estaban por debajo de los precios de 1999). 
Uno de los principales inversores es Douglas Tomkins a través de su fundación "Tomkins Conservation". Este inversionista sigue dos mecanismos distintos para sus adquisiciones, siguiendo un filosofía de "ecología profunda", es decir la naturaleza sin intervención humana, para lo cual transforma las tierras para dejarlas en un estado lo más "virgen" y silvestre posible. Por un lado, adquiere grandes estancias productivas que recupera introduciendo especies en extinción y reacondicionando el paisaje, la flora y la fauna. Una parte de estas estancias las arrienda para actividades productivas sustentables y ecológicas (es decir, que sigan determinados estándares orgánicos y de manejo de recursos), y otra parte las destina al eco-turismo de lujo. De esta forma, al igual que como vimos en el caso de las empresas productivas que transformaban la tierra para aumentar su valor, en este caso sucede lo mismo y esto le ha permitido a Tomkins vender miles de hectáreas "recuperadas" en Argentina en los últimos años obteniendo importantes ganancias (Tomkins Conservation 2013, 2014).

Por otro lado, este inversor adquiere grandes extensiones de tierras en lugares estratégicos en términos de recursos naturales, belleza paisajística y alto potencial ecológico (muchas de las cuales son adyacentes a parques nacionales ya existentes) para, en teoría, luego de recuperadas donar a los Estados para crear parques nacionales. La investigación de (García 2004) mostró que, en realidad, esta compañía (asociada con fundaciones ecologistas nacionales, como Fundación Vida Silvestre) entrega provisoriamente las tierras al Estado (ya sea nacional o provincial) bajo la figura del fideicomiso imponiéndole una serie de condicionalidades de muy difícil cumplimiento (por ejemplo, establecer "parques marinos" -parques con mayor superficie de agua que de tierra- en menos de 3 años). Si las mismas no se efectivizan en un determinado plazo, el contrato permite a Tomkins recuperar esas tierras.

Además de Tomkins, dentro de este objetivo se encuentran otros grandes magnates que han adquirido tierras para explotar los paisajes de la Patagonia argentina a través de mega emprendimientos "eco-turísticos" de lujo, sólo accesibles a turistas de altos ingresos. Este es el caso de Ted Turner, Joseph Lewis y el holandés Hubert Gosse. El caso de Joseph Lewis ha resultado sumamente conflictivo pues, dentro del predio que adquirió del Estado se encuentra el Lago Escondido (público, según la legislación argentina), y el empresario cercó los accesos públicos al mismo para impedir el acceso libre y gratuito a aquel paisaje natural (un día en el complejo de Lewis cuesta más de US 1700 ). En los tres casos se trata de grandes extensiones (muchas adquiridas a los propios Estados provinciales) con grandes reservorios de agua dulce y otros recursos estratégicos.
Si bien en Argentina no existe aún un mercado de bonos de carbono, el gobierno ya ha enviado en el año 2013 una propuesta a Naciones Unidas para la gestión del programa REDD+ ("Reducción de Emisiones por Deforestación y Degradación") en el país (programa de aquel organismo que otorga financiamiento a los Estados y los propietarios de tierras que cumplan con determinadas normas en términos de forestación). Además, la Ley de Bosques sancionada en 2007 también prevé el otorgamiento de fondos para los dueños de tierras en pago por los servicios ambientales que brindan los bosques. ${ }^{10}$ Todos estos incentivos se suman a la obtención de ganancias derivadas de la explotación de emprendimientos turísticos y otros fondos de organismos internacionales que los dueños de grandes reservorios de recursos naturales pueden obtener por su conservación. Al igual que en el objetivo anterior, se trata de inversiones para producir bienes y servicios destinados al mercado. Es decir, más allá de las definiciones personales que tienen este tipo de inversores sobre sí mismos y sobre sus inversiones, poco de filantropía parece haber en las adquisiciones de tierras con fines ecológicos.

\section{3) Garantizar el abastecimiento de materias primas a sus países de origen}

Una de las novedades del acaparamiento de tierras por parte extranjeros en la década del 2000 son las adquisiciones con el fin de garantizar el abastecimiento por parte de determinados países, sobre todo países que en los últimos años vienen experimentando procesos de fuerte de crecimiento e industrialización y que requieren del abastecimiento constante de materias primas para sostener estas tasas. ${ }^{11}$

\footnotetext{
${ }^{10}$ Según esta ley, se incluyen como servicios ambientales de los bosques: la regulación hídrica; la conservación de la biodiversidad; la conservación del suelo y de calidad del agua; la fijación de emisiones de gases con efecto invernadero; la contribución a la diversificación y belleza del paisaje; y la defensa de la identidad cultural (Poder Legislativo Nacional 2007).

${ }^{11}$ Como veremos en cada uno de los casos siguientes, estos países podrían entrar en lo que Marini (1977) denominó “centros medianos de acumulación", que por su alto nivel de composición de capital en el aparato productivo y su política expansionista pueden ser considerados "subimperialistas". Estos países, según Marini, requieren de Estados que aseguren la realización de la reproducción del capital, "asegurando campos de inversión en el exterior mediante operaciones de las empresas estatales, créditos intergubernamentales o garantías a operaciones privadas en América Latina y África" (p. 19). Como veremos, esto es exactamente, lo que los Estados chino, saudí e indio están haciendo con sus inversiones en tierras en Argentina.
} 
Tabla 4. Países que adquieren tierras en Argentina para garantizar abastecimiento de materias primas, hectáreas y $\%, 2002-2013$

\begin{tabular}{lcc}
\hline País & Hectáreas & Porcentaje \\
\hline China & 320000 & 38.2 \\
India & 273700 & 32.7 \\
Arabia Saudita & 212306 & 25.4 \\
Corea del Sur & 20000 & 2.4 \\
Japón & 11000 & 1.3 \\
Total & 837006 & 100 \\
\hline
\end{tabular}

Fuente: Elaboración a partir de la base de datos construida.

En primer lugar está China, que comenzó en el 2011 a hacer grandes adquisiciones de tierra en el país. Desde el 2010, China comenzó a invertir en Argentina en múltiples sectores estratégicos para el abastecimiento de materias primas necesarias para el proceso de acumulación de capital del país asiático. De esta forma, había invertido en el sector energético (compró el 50\% de la petrolera argentina Bridas, del empresario Bulgheroni, y participaciones en la filial argentina de Occidental Petroleum, Exxon Mobil y Electroingeniería), en el sector de finanzas (el banco chino ICBC compró el 80\% de Standard Bank Argentina S. A.), en el sector de transporte (trenes y jointventure con la automotriz argentina SOCMA), en el sector agrícola (jointventure con CRESUD) y en el sector químico (The Heritage Foundation 2014).

En el año 2010, la empresa estatal china Heilongjiang Beidahuang State Farm Business Trade Group Co. firmó un acuerdo de cooperación con la provincia argentina de Río Negro para un proyecto agroalimentario que consistía en la inversión, por parte de los inversores chinos, en un sistema de infraestructura de riego para más de 300000 hectáreas a lo largo de cinco valles lindantes al río Negro. Para realizar esto iban a tener múltiples facilidades por parte del gobierno y la concesión de la zona portuaria de San Antonio Este "sin cargo alguno" por 50 años (con renovación automática) (Gobierno de la provincia de Rio Negro 2010).

El acuerdo consistía en lo siguiente: la empresa realizaría la inversión en el sistema de riego y la misma se iba a computar como un préstamo a los productores que se vieran beneficiados por dicho sistema. Los productores seguirían produciendo ellos mismos sus tierras, pero a cambio del préstamo, debían producir sólo lo que la empresa china les pidiera y vender exclusivamente a ellos toda la producción. Si los productores no estaban dispuestos a esto podían vender o alquilar su tierra siempre que el comprador o arrendador se comprometa a producir los bienes encargados por la empresa china; de lo contrario las tierras podían ser expropiadas por el Estado. Además, los productores debía ceder el $30 \%$ de sus tierras como garantía por la inversión china y pagar, durante 20 años, la deuda por esta inversión (si no querían o no podían hacerlo, tenían la posibilidad de entregar el $30 \%$ de la tierra que habían puesto en garantía).12

Es decir, si bien la empresa china no se apropiaba legalmente del $100 \%$ de esta tierra, sí pasaba a tener el control absoluto de la misma y de la producción. Los propietarios originales de la tierra devendrían en productores tercerizados produciendo por encargo para el capital de origen chino (de productores independientes a "empleados tercerizados" de la empresa). Entonces, de acuerdo a la particularidad que tiene este acuerdo, parecería que el principal objetivo del capital chino, además de obtener una rentabilidad por la inversión en el sistema de riego, es asegurarse el abastecimiento de materias primas necesarias para su propio proceso de acumulación de capital hacia adentro de su país. El proceso de urbanización e industrialización en China aumentó las necesidades de materias primas y alimentos tanto por el crecimiento de la demanda para abastecer los procesos industriales, como también por el aumento en el consumo derivado de mejores niveles de ingresos para alguna parte de la población y por la mayor presión sobre la tierra cultivable que se ha dado hacia el interior del país. Al mismo tiempo, resulta cada vez más necesario para aquella economía encontrar nuevas oportunidades de inversión para colocar el capital acumulado a partir del proceso de reformas estructurales de mercado y de superexplotación del trabajo que allí se da (pago por debajo del valor de la fuerza de trabajo y alta intensidad laboral). En este sentido, las inversiones externas en adquisición de tierras para la producción de materias primas atiende a estas dos necesidades: asegura el abastecimiento de las materias primas necesarias y ofrece una oportunidad rentable de inversión para expandir el capital chino. ${ }^{13}$

\footnotetext{
12 Debe constatarse la lógica del acuerdo para los productores, que logran una valorización de sus tierras gracias a la tecnificación y se aseguran ventas por dos décadas. El Estado argentino, en lugar de definir autónomamente estas políticas para sus productores, prefiere darle facilidades a un Estado extranjero.

13 Según Zheng Fengtian, profesor de la universidad de Pekín: "China quiere seguir siendo autosuficiente en alimentos como el arroz, fundamental en la dieta china y, por tanto, estratégico. Pero en otros productos, como la soja o el maíz, que sirven para alimentar a los animales, no será posible. Hay que importar, pero ¿cómo hacerlo? Hay tres estrategias, muy similares a como China se ha abastecido de petróleo: comprar en el mercado mundial, adquirir participaciones en empresas alimenticias mundiales para controlarlas $\mathrm{y}$, por último, comprar tierra en otros países. De todas, la menos deseable es comprar en el mercado mundial, por cuestiones de seguridad. ¿Qué pasaría si los grandes productores de alimentos como Estados Unidos o Brasil deciden prohibir sus exportaciones?" (Cardenal \& Araújo 2011).
} 
Algo similar ocurre con las inversiones árabes e indias en tierras en Argentina, pero a diferencia del caso chino de inversión con empresas estatales, en estos casos se trata de inversiones de capitales privados con apoyo de los Estados. En el año 2011 el sheik árabe Mohammed Al-Khorayef firmó un convenio con el gobierno de la provincia del Chaco para explotar 200000 hectáreas en la región del bosque Impenetrable para producir granos y exportarlos al país árabe, comprometiéndose a invertir en infraestructura de riego. ${ }^{14} \mathrm{El}$ proyecto del inversor árabe es parte de una política de aquel país denominada "Iniciativa del rey Abdullah para la seguridad alimentaria nacional", que consiste en la provisión por parte del gobierno de fondos, crédito y logística a inversores privados saudíes para que inviertan en el extranjero en agricultura. El objetivo es formar una reserva estratégica de materias primas alimenticias para hacer frente a las necesidades de alimentación y para evitar futuras crisis alimentarias (sobre todo, por no tener control sobre el precio internacional de los alimentos). Esta política surge a partir de la eliminación de la política de subsidios que el gobierno árabe tenía con los productores saudíes, lo cual aumentó las necesidades de importación de alimentos de aquel país. Es decir, nuevamente, al igual que en el caso de China, la adquisición de tierras en Argentina responde a factores relativos a los procesos de acumulación de los países inversores.

Por último, en el caso de India, se trata de tierras adquiridas, principalmente, por el grupo Walbrook durante la crisis argentina en 2002, por lo que los terrenos estaban muy devaluados. Apoyados por el gobierno indio, los inversores privados comenzaron a adquirir tierras en Argentina para producir papas y ganado caprino para abastecer a India y sostener el acelerado proceso de urbanización que se da en aquel país.

En los tres casos, queda claro que el territorio argentino y su uso quedan supeditados a las necesidades de acumulación y geoestratégicas de otros países, reafirmando el lugar dependiente de Argentina. Debe llamarse la atención sobre el hecho de que los tres casos referidos no son países que actualmente se consideren centros hegemónicos del mundo, sino países en ascenso. Argentina queda supeditada a ambos tipos de países.

Encontramos, pues, que el fenómeno del acaparamiento de tierras en Argentina durante la década del 2000 responde a 3 objetivos diferenciados: (i) Participar del negocio que significa el aumento de los precios y la demanda mundial de

\footnotetext{
14 Al igual que en el caso de Río Negro, la inversión del megaemprendimiento agrícola se realiza (con fondos árabes) a través de un préstamo al gobierno provincial por 12 años.
}

alimentos y minerales que se dio durante la década del 2000 por medio de la producción y extracción de los mismos y obtener ingresos derivados de los "servicios ambientales" que brindan las tierras para conservación. (ii) Valorizar el capital en el negocio inmobiliario que implica el aumento del precio de la tierra, tanto por el aumento en el precio de los alimentos como por la inversión en infraestructura (tanto en el caso de las tierras para producción de alimentos como las tierras para conservación). (iii) Garantizar el abastecimiento de alimentos y materias primas, que permitan sostener los procesos de acumulación de capital en los propios países de origen de los inversores. Tres objetivos que responden a decisiones fuera del alcance de un país como Argentina (aunque facilitadas, claro, por las políticas de incentivo que aquí se apliquen) y que implican la transferencia hacia el exterior del valor producido internamente (tanto en términos de ganancias como de rentas de la tierra). Asimismo, los tres objetivos refuerzan el rol de Argentina como reservorio de recursos naturales y como abastecedora de materias primas, una posición claramente subordinada en el orden mundial.

\section{5) Reflexiones finales}

A partir de la devaluación de 2002 aumentaron las adquisiciones de tierras por parte de extranjeros en Argentina. Quienes realizaron estas inversiones fueron, principalmente, Estados Unidos y nuevos inversores en la escena nacional, como son China, India y Arabia Saudita, que orientaron sus inversiones a regiones de frontera agrícola dentro del país, produciendo la "valorización total del territorio argentino": ya no queda ningún espacio del país que no esté a disposición del modo de desarrollo. Luego de la devaluación del 2002 en el país y a partir del ascenso de nuevos países en el escenario del capitalismo mundial (como China o India), el panorama de la adquisición de tierras cambia con respecto a la década anterior, en términos de los objetivos: se duplican las tierras para producción agropecuaria, ganan importancia las adquisiciones para explotaciones mineras y surge un nuevo objetivo antes inexistente, el control de tierras para garantizar el abastecimiento de materias primas y alimentos de los países inversores.

Respecto a los objetivos de las inversiones, encontramos que el fenómeno del acaparamiento de tierras en Argentina (2002-2013) responde a tres objetivos: (i) participar del negocio que significa el aumento de precios y la demanda mundial de alimentos y minerales por medio de la producción y extracción de los mismos y por medio de la obtención de ingresos derivada de los "servicios ambientales" de las tierras para conservación. (ii) Valorizar el capital en el negocio inmobiliario que implica el aumento 
en el precio de la tierra. Y (iii) garantizar el abastecimiento de alimentos y materias primas, que permitan sostener los procesos de acumulación de capital en los propios países de origen de los inversores. A las inversiones que persiguen este último objetivo las definimos como "inversiones con demanda asegurada" y esa demanda asegurada responde a necesidades específicas de un proceso de valorización en otra economía que requiere, para ello, de garantizarse el abastecimiento de ciertos bienes. Éste último resulta un hallazgo muy relevante de la investigación porque obliga a preguntarnos respecto del futuro de este fenómeno: ¿el hecho de que hayan comenzado a disminuir los precios de las materias primas en los últimos años implicará un retroceso o desaceleración del acaparamiento de tierras en países dependientes? o, ¿no obstante la caída de los precios, va a continuar e incluso intensificar, en la medida en que esta modalidad de inversión sea funcional a los procesos de acumulación de algunos países (que se están posicionando como centrales en el orden mundial)?

Los tres objetivos anteriores responden a decisiones tomadas fuera del alcance de un país como Argentina, y refuerzan el rol del país como reservorio de recursos naturales y como abastecedora de materias primas. De conjunto, entonces, el proceso muestra la profunda imbricación del modo de desarrollo argentino en su fase actual con el proceso de acaparamiento de tierras. De hecho, este proceso profundiza en esta fase la dependencia externa que caracteriza al modo de desarrollo, dejando cada vez menos espacio al control del patrimonio nacional con base en decisiones soberanas.

\section{REFERENCIAS}

ADECOAGRO SA. 2010. United States Securities and Exchange Commission Form 20-F. Washington, D.C.: United States Securities and Exchange Commission.

ADECOAGRO SA. 2011. United States Securities and Exchange Commission Form 20-F. Washington, D.C.: United States Securities and Exchange Commission.

ADECOAGRO SA. 2013. United States Securities and Exchange Commission Form 20-F. Washington, D.C.: United States Securities and Exchange Commission.

ASOCIACIÓN MAPU. 2014. Santa Rosa Recuperada. Recuperado a partir de http://www.santarosarecuperada.com.ar/antecedentes_his toricos.html
AZPIAZU, D. SCHORR, M. \& MANZANELLI, P. 2012. Concentración y extranjerización. Buenos Aires: Capital Intelectual.

BARBERI, F. CASTRO, Y. \& ÁlVAREZ, J. M. 2013. Acaparamiento e inversión extranjera en tierras. Propuestas para su regulación en Colombia. En A. PESQUERA (Ed.), Reflexiones sobre la ruralidad y el territorio en Colombia. Problemáticas y retos actuales 115-161. Bogotá: OXFAM.

BORRAS, S. KAY, C. \& GÓMEZ, S. 2012. Land grabbing and global capitalist accumulation: key features in Latin America. Canadian Journal of Development Studies/Revue canadienned'études du developpement 33(4): 402-416.

BURACHIK, G. 2009. Economía aplicada. La economía argentina en el corto y en el largo plazo. Bahía Blanca: EDIUNS.

BURACHIK, G. CANTAMUTTO, F. J. COSTANTINO, A. FERNÁNDEZ MASSI, M. PÉREZ ARTICA, R. \& RECALDE, M. 2010. Un análisis del proceso reciente de «Argentinización» en el sector servicios. En III Jornadas de Economía Crítica (p. 23). Rosario, Argentina.

CANTAMUTTO, F. J. \& COSTANTINO, A. 2014. Modos de desarrollo: conceptualización y aplicación al caso argentino. En I Congreso Latinoamericano de Estudiantes de Posgrado en Ciencias Sociales (CLEPSO) (p. 32). México: FLACSO México.

CARDENAL, J. P. \& ARAÚJO, H. 2011. China y su silenciosa conquista del mundo (p. 320). Barcelona: Crítica.

CLEMENTS, E. A. \& FERNANDES, B. M. 2013. Land Grabbing, Agribusiness and the Peasantry in Brazil and Mozambique. Agrarian South: Journal of Political Economy 2(1): 41-69.

COSTANTINO, A. 2012. La pampa sigue ancha y ajena: la persistencia del poder terrateniente en la región pampeana argentina durante la etapa de sojización. Tesis de Maestría en Ciencias Sociales. Facultad Latinoamericana de Ciencias Sociales. Sede México.

COSTANTINO, A. 2014. Land Grabbing in Latin America: Another Natural Resource Curse? Agrarian South: Journal of Political Economy 3(1): 17-43.

COSTANTINO, A. 2015a. The dark side of the boom: land grabbing in dependent countries in XXI century. International Critical Thought, 5(4). 
Ambiente y Sostenibilidad 2015 (5): 43-56

Revista del Doctorado Interinstitucional en Ciencias Ambientales

ISSN:2339-3122

COSTANTINO, A. 2015b. La extracción del territorio. Extranjerización de la tierra y modo de desarrollo en Argentina, 2002-2013. Tesis de doctorado en Investigación en Ciencias Sociales. FLACSO, México.

COSTANTINO, A. \& CANTAMUTTO, F. J. 2010. El MERCOSUR agrario: ¿Integración para quién? Íconos (38): 67-80.

CRESUD S. A. 2010. United States Securities and Exchange Commission Form 20-F. Washington, D.C.: United States Securities and Exchange Commission.

DEPARTAMENTO NACIONAL DE PLANEACIÓN. 2010. PLAN NACIONAL DE DESARROLLO 2010-2014 «Prosperidad para todos». Bogotá: Departamento Nacional de Planeación de Colombia. Recuperado a partir de https://www.dnp.gov.co/Plan-Nacional-de-

Desarrollo/PND-2010-2014/Paginas/Plan-Nacional-De2010-2014.aspx

EJOLT PROJECT. 2014. Environmental Justice Atlas. Recuperado 20 de septiembre de 2014, a partir de http://ejatlas.org/

FAIRHEAD, J. LEACH, M. \& SCOONES, I. 2012. Green Grabbing: a new appropriation of nature? Journal of Peasant Studies 39(2): 237-261.

GARCÍA, M. 2004, agosto 11. Douglas Tompkins y su reinado patagónico. Rebelión.

GOBIERNO DE LA PROVINCIA DE RIO NEGRO. 2010. Acuerdo de Cooperación para el Proyecto de Inversión Agroalimenticio entre Heilongjiang Beidahuang State Farm Business Trade Group Co. y el gobierno de la provincia de Río Negro, Argentina.

GRAJALES, J. 2011. The rifle and the title: paramilitary violence, land grab and land control in Colombia. Journal of Peasant Studies 38(4): 771-792.

HARVEY, D. 2004a. El nuevo imperialismo. Ediciones AKAL. Recuperado a partir de http://books.google.com.mx/books/about/El_nuevo_impe rialismo.html?id=2LfhY75vap0C\&pgis $=1$

HARVEY, D. 2004b. El «nuevo» imperialismo: acumulación por desposesión. Socialistregister, 99-129.

ILC. 2013. Land Portal. Recuperado a partir de http://landportal.info/es/node/10290
IÑIGO CARRERA, J. 2008. Terratenientes, retenciones, tipo de cambio, regulaciones específicas. Los cursos de apropiación de la renta de la tierra agraria 1882-2007.

KELLY, A. B. 2011. Conservation practice as primitive accumulation. Journal of Peasant Studies 38(4): 683-701.

MARINI, R. M. 1977. La acumulación capitalista mundial y el subimperialismo. Cuadernos políticos (12): 26.

MARINI, R. M. 1991. Dialéctica de la dependencia. México: Ediciones Era.

MARTÍNEZ-ALIER, J. 2009. Lenguajes de valoración. El viejo topo (253): 95-103.

MURMIS, M. \& MURMIS, M. R. 2010. El caso de Argentina. En F. SOTO BAQUERO \& S. GÓMEZ (Eds.), Dinámicas del mercado de la tierra en América Latina y el Caribe: concentración y extranjerización (pp. 15-59). FAO.

OLZAK, S. 1989. Analysis of events in the study of collective action. AnnualReview of Sociology (15): 119-141.

PODER LEGISLATIVO NACIONAL. Ley de presupuestos mínimos de protección ambiental de los bosques nativos (2007). Senado y Cámara de Diputados de la nación Argentina.

SALINAS-ABDALA, Y. 2012. El caso de Colombia. En F. SOTO BAQUERO \& S. GÓMEZ (Eds.), Dinámicas del mercado de la tierra en América Latina y el Carible: concentración y extranjerización (pp. 179-209). FAO.

SAUER, S., \& PEREIRA-LEITE, S. 2011. Agrarian structure, foreign land ownership, and land value in Brazil. En International Conference on Global Land Grabbing. Land Deal Politics Initiative and Journal of Peasant Studies.

THE HERITAGE FOUNDATION. 2014. China global investment tracker. Recuperado 27 de septiembre de 2014, a partir http://www.heritage.org/research/projects/china-globalinvestment-tracker-interactive-map

TILLY, C. 2002. Event catalogs as theories. Sociological Theory 20(2): 248-254.

TOMKINS CONSERVATION. 2013. Tomkins Conservation. Recuperado 20 de septiembre de 2014, a partir de http://www.tompkinsconservation.org/home.htm 
TOMKINS CONSERVATION. 2014. The Conservation Land Trust. Recuperado 20 de septiembre de 2014, a partir de http://www.theconservationlandtrust.org/esp/our_missio n.htm

WILKINSON, J. REYDON, B. \& DI SABBATO, A. 2012. El caso de Brasil. En F. SOTO BAQUERO \& S. GÓMEZ (Eds.), Dinámicas del mercado de la tierra en América Latina y el Carible: concentración y extranjerización (pp. 105-145). FAO.

ZOOMERS, A. 2010. Globalisation and the foreignisation of space: seven processes driving the current global land grab. Journal of Peasant Studies 37(2): 429-447. 